\title{
Effects of Packaging Materials and Disinfectants on Quality Changes of Ceylon Spinach (Basella alba L.) during Storage
}

\section{Tong Thi Anh Ngoc \& Phan Thi Thanh Que}

Food Technology Department, Faculty of Agriculture, Can Tho University, Can Tho, 94115, Vietnam

\begin{abstract}
The objectives of the study were to determine the effective washing disinfectant (chlorine dioxide and $\mathrm{r}$ peracetic acid) in reducing total aerobic counts, E. coli and coliform, and then to test different packaging materials, namely polypropylene (PP), high density polyethylene (HDPE), and low density polyethylene (LDPE), on the quality and shelf-life of Ceylon spinach. The results showed that washing Ceylon spinach with $100 \mathrm{ppm}$ peracetic acid solution for five minutes significantly reduced $E$. coli and coliform counts (reduction of 1.1 and $>2 \log \mathrm{CFU} \mathrm{g}{ }^{-1}$, respectively). Ceylon spinach packed in HDPE material might optimally prolong the shelf-life up to 7 days whereas spinach packed in LDPE was recommended if used within 6 days at $10 \pm 1^{\circ} \mathrm{C}$.
\end{abstract}

\section{Keywords}

Ceylon spinach, microbial counts, packaging materials, peracetic acid, quality, storage

\section{Introduction}

Basella alba L. is an important green leafy vegetable commonly found in the tropical regions of the world (Deshmukh \& Gaikwad, 2014; Varalakshmi, 2016). In Vietnam, there are more than 100 industrial sectors of vegetable production with a total capacity of 300,000 tons each year (MARD, 2018). Fresh vegetables are sold in local markets, supermarkets, and retailers, etc. in Vietnam. Most of the vegetables marketed are produced as primary production and are rinsed and stored under ambient temperatures in local markets or refrigerated conditions in supermarkets. For convenience and safety reasons, it is necessary to produce ready-to-use vegetable products as minimally processed vegetables, especially Basella alba (Ragaert et al., 2007; Kakade et al., 2015).

Minimally processed vegetables, which includes vegetables being selected, washed and dried, and packaged with sealed. These steps may not be efficient to eliminate contamination 
on minimally processed vegetables (Graça et al., 2017). Hence, washing vegetables with disinfectants could potentially reduce or eliminate the microbial loads on vegetable products as much as possible (Tong et al., 2015; Tong et al., 2018). Chlorine (the most common disinfectant) and peracetic acid (an alternative disinfectant) have been studied intensively on vegetables (Arturo-Schaan et al., 1996; Li et al., 2001; Allende et al., 2004; Jin \& Lee, 2007). Though the use of chlorine is reasonable regarding cost and efficiency, the chlorination process has some negative effects, such as the formation of carcinogenic by-products, skin irritation, and negative respiratory tract effects (Tong, 2015). Unlike chlorine, peracetic acid is harmless and produces environmentally friendly residues; it is a promising and widespread substitute for chlorine.

In addition to using sanitizing treatments as chemical interventions in the reduction of microbial loads on vegetables, packing vegetables in plastic containers as a physical intervention could be inacted to extend the shelf-life of minimally processed vegetables. The storage of the minimally processed vegetables can be combined with refrigeration in order to reduce the respiration rate and inhibit microbial growth (Barbosa et al., 2011). However, the types of packaging materials and packaging methods also partly affect the quality changes and the shelf-life of products during storage (Suryawanshi, 2008; Costa et al., 2011; Muizniece-Brasava et al., 2013), particularly for vegetables (Piagentini \& Güemes, 2002; Jacobsson et al., 2004), meat (Kotzekidou \& Bloukas, 1996), and fish products (Ly \& Tong, 2017).

The objectives of the present study were to determine the most effective disinfectant in reducing the total aerobic counts of Escherichia coli (E. coli) and coliform on Ceylon spinach vegetables (Basella alba) in preliminary treatments and identify the proper packaging materials that can minimize the changes in quality and organoleptic properties of Ceylon spinach vegetables during storage.

\section{Materials and Methods}

\section{Experimental design}

\section{Decontamination efficacy}

Ceylon spinach (Basella alba) was grown on a farm-scale in Chau Thanh A district, Hau Giang province, Vietnam and was harvested after 30-35 days of cultivation. The Ceylon spinach plants $(35-50 \mathrm{~cm}$ in length) were harvested from January to April 2018 and transported to the laboratory at the Food Technology Department, Can Tho University. Preparation and disinfection were carried out in a cleanroom at $28-30^{\circ} \mathrm{C}$. Three separate experiments were repeated independently. The white rust, downy mildew, and yellow leaves were removed prior to washing the plants in tap water (for 60 seconds) to remove the soil, sand, and foreign matters. The excess water on the surface of the Ceylon spinach was drained manually using a salad spinner (Japan) for one minute. Thereafter, the Ceylon spinach was dipped in chlorine dioxide (5\%, Thailand; $\mathrm{pH}$ adjusted to 6.5 via acetic acid) or peracetic acid $(12 \%$, Korea) at a concentration of $100 \mathrm{ppm}$ for five minutes with the ratio of 1:10 of fresh-cut spinach and the solution. Then, the Ceylon spinach was rinsed with potable water (commercial drinking water produced by Can Tho University) with the same ratio used with the disinfectant for one minute to remove any disinfectant residues and centrifuged for another minute.

In each experiment, the decontaminated Ceylon spinach was compared to the unwashed and water washed samples. Effective decontamination was evaluated based on the reduction of microbial counts, i.e. total mesophilic counts, E. coli and coliform counts, and organoleptic quality.

\section{Storage of the Ceylon spinach}

Similar to the procedure described above, the Ceylon spinach plants were washed in the selected disinfectants and were packed in different packaging materials: PP (polypropylene, thickness of $25 \mu \mathrm{m}$ ), HDPE (high density polyethylene $67 \%$, thickness of $35 \mu \mathrm{m}$ ), or LDPE (low density polyethylene, thickness of $40 \mu \mathrm{m})$ with package sizes of 
$18 \times 21 \mathrm{~cm}$. Each independent experiment, twenty-four sealed bags of the Ceylon spinach plants packed on three above materials weighing $50 \mathrm{~g}$ each were placed in a refrigerator (Sanaky, Vietnam) at $10 \pm 1{ }^{\circ} \mathrm{C}$. The control samples were placed in plastic disks but were not sealed, and then stored in the same refrigerator. The three different storage experiments were repeated independently.

\section{Analytical methodology}

\section{Physical and chemical qualities of the Ceylon spinach}

The initial weight and storage weight of each sample were determined on the sampling day prior to analysis using a balance (OHAUS, China). The extent of spoilage was calculated by weighing the amount of spoiled leaves from each stored sample.

The $\mathrm{pH}$ of the Ceylon spinach was determined by an electronic $\mathrm{pH}$ meter (Vernier, USA).

The vitamin C content $(\mathrm{mg} / 100 \mathrm{~g}$ dry weight) of the Asian spinach was analyzed by titration methods with 2.6-dichlorophenolindophenol reagents.

The color of the whole leaves was measured using a spectrophotometer-colorimeter (model NR60CP, China). The overall color difference $(\Delta E)$ in color spaces $\mathrm{L}^{*}, \mathrm{a}^{*}$, and $\mathrm{b}^{*}$ was calculated according to the following equation (1):

$$
\Delta E=\sqrt{\left(L^{*}-L\right)^{2}+\left(a^{*}-a\right)^{2}+\left(b^{*}-b\right)^{2}}
$$

where $\mathrm{L}^{*}, \mathrm{a}^{*}, \mathrm{~b}^{*}$ and $\mathrm{L}, \mathrm{a}, \mathrm{b}$ are the measured values of the samples on day 0 and day of sampling, respectively.

\section{Microbiological analysis}

A $15 \mathrm{~g}$ composite sample collected from different parts of each spinach sample was transferred aseptically to a Stomacher bag by means of sterile scalpels and tweezers. One hundred thirty-five (135) $\mathrm{mL}$ of sterile Maximum Recovery Diluent (MRD; Merck, Darmstadt, Germany) was added and the mixture was homogenized for $1 \mathrm{~min}$. A tenfold serial dilution was made from the sample in the MRD. The total aerobic mesophilic counts
(TMC), total yeasts and molds, and total coliform and $E$. coli counts were determined by pour plating the decimal dilutions onto Plate Count Agar (PCA, India, Himedia), Yeast Extract Glucose Chloramphenicol Agar (YGC, Merck, Darmstadt, Germany), and Chromocult® Coliform Agar ES (Merck, Darmstadt, Germany), respectively. The pour plates were incubated for $2-3$ days at $37^{\circ} \mathrm{C}$ to determine the TMC and total yeasts and molds, and for $24 \mathrm{~h}$ to determine the total coliform and E. coli. Microbial counts were reported as $\log$ CFU g ${ }^{-1}$ of tissue.

\section{Sensory evaluation}

After the spinach samples were washed with one of the two disinfectants mentioned above at a concentration of $100 \mathrm{ppm}$ for $5 \mathrm{~min}$ (the preliminary treatment), the sensory quality of the spinach samples, general appearance, color, odor, and texture, were evaluated by 18 19 panelists who participated in triangle tests. After being washed with a disinfectant, the samples were rinsed in tap water for one minute before the sensory tests. In all cases, a set of three samples of the vegetable (each sample $c a$. $50 \mathrm{~g}$ ), randomly coded with 3-digit numbers, was presented to each panelist. The panelists were told that two of the samples were similar and were asked to identify the odd sample. The number of correct answers was compared to the number expected by using a statistical table to achieve a significant answer (5\% level) according to the BS ISO 4120:2004.

The sensory evaluation of the Ceylon spinach during storage was implemented by scoring methods. The spinach was scored on a scale from 0 to 5 , with 0 being the lowest and 5 being the highest. A descriptive table with the lowest and highest quality attributes was provided. Each assessment was carried out by ten panelists and they were also asked to state whether or not the spinach was acceptable. This was used to determine the shelf-life of the products.

\section{Statistical analysis}

Data were subjected to one-way analysis of variance (ANOVA) using the Statgraphics Centurion 15.1 program (U.S.A.). LSD (Least 
Significant Difference) test was applied for pairwise comparisons of means at $\mathrm{P} \leq 0.05$. All results were reported as the mean values \pm standard deviations.

\section{Results and Discussion}

\section{Effects of the chlorine dioxide and peracetic acid disinfectants on the microbial counts of the spinach}

Chlorine dioxide and peracetic acid are considered alternative sanitizers because of their strong oxidation capacities and lower risk of forming harmful by-products (Monarca et al., 2002; Silveira et al., 2008). Both disinfectants are safe and create environmentally friendly residues (Demirci \& Ngadi, 2012).

The antimicrobial effects of chlorine dioxide and peracetic acid (PAA) were evaluated on the Ceylon spinach (Figure 1). The initial total mesophilic counts (TMC), coliform counts, and E. coli counts on unwashed Ceylon spinach were $7.1 \pm 0.12,4.9 \pm 1.23$, and $2.9 \pm 1.02 \log \mathrm{CFU} \mathrm{g}{ }^{-1}$, respectively. The TMC on the Asian spinach washed in tap water, chlorine dioxide, and PAA were $6.9 \pm 0.41,6.4$ \pm 0.81 , and $6.5 \pm 0.06 \log \mathrm{CFU} \mathrm{g}^{-1}$, respectively. The coliform counts on the Ceylon spinach washed in tap water, chlorine dioxide, and PAA were $4.7 \pm 0.7,4.1 \pm 1.14$, and $3.8 \pm 0.3 \log$ CFU g ${ }^{-1}$, respectively. The E. coli counts on the Ceylon spinach washed in tap water, chlorine dioxide, and PAA were $1.6 \pm 1.13,1.1 \pm 0.15$,

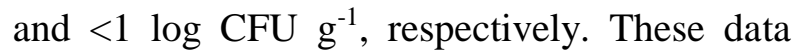
indicate that the microbial counts on Ceylon spinach washed in tap water (control samples) were not reduced significantly. The chlorine dioxide and peracetic acid solutions were not effective in reducing TMC but significantly reduced coliform and $E$. coli counts on the Ceylon spinach. Surprisingly, a significant reduction of $E$. coli was observed (detection

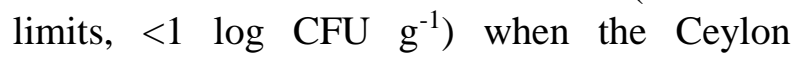
spinach was washed with peracetic acid. This result was probably because peracetic acid has a stronger oxidation capacity and is less affected by organic matter than chlorine dioxide (Kitis, 2004). The obtained results are in agreement with the previous study of Sapers (2001) who reported that cucumbers washed in chlorine dioxide water resulted in less than $1 \log$ unit of various microbes (i.e. total aerobic counts, lactic acid bacteria, yeast and molds) on product surfaces. Additionally, the microbial reductions for aerobic bacteria coliform, yeast and molds on fresh-cut celery, cabbage, and potatoes washed in $80 \mathrm{ppm}$ of peracetic acid were less than $1.5 \log$ units (Joshi et al., 2013).

The sensory qualities of the Ceylon spinach samples after being washed with chlorine dioxide or peracetic acid were evaluated using triangle tests. The results in Figure 2 show that the Ceylon spinach samples washed with the two solutions were not significantly different compared to those washed with tap water. The number of correct responses was lower than the required number of correct responses to achieve a significant difference. Based on these results, peracetic acid is recommended as a suitable sanitizer to wash Ceylon spinach for further storage.

\section{Physical and chemical changes of the spinach during storage}

\section{Weight loss and rate of spoilage during storage}

The weight loss and rate of spoilage of the spinach were measured by the change in weight of the samples over the storage period at $10 \pm$ $1^{\circ} \mathrm{C}$. The percent of weight loss and rate of spoilage of the Ceylon spinach are shown in Figure 3 and Figure 4, respectively. The highest weight loss (17.28\%) and almost complete spoilage (99.24\%) were observed in the control samples (not packed) after 3 days. The direct contact of the Ceylon spinach with cool air resulted in a rapid loss of moisture during storage. After 7 days of storage, the weight loss $(6.89 \%)$ and rate of spoilage $(44.21 \%)$ of the Ceylon spinach packed in LDPE were higher than the samples packed in PP $(2.56 \%$ and $22.53 \%$, respectively) and HDPE $(4.27 \%$ and $12.53 \%$, respectively). It is well known that the rate of water vapor transmission of LDPE is higher than the other packaging materials, thus, the samples packed in LDPE had a higher loss of moisture and higher spoilage rate (Piagentini \& Güemes, 
2002). In addition, the loss of moisture can cause undesirable changes in color, soft structure, and loss of nutritional quality (Nagar et al., 2012).

Color and $\mathrm{pH}$ changes of the spinach during storage

The color changes of the spinach during storage shown in Table 1 reveal that the overall color difference $(\Delta \mathrm{E}=2.94)$ of the control samples was not different with the samples contained in the PP and HDPE packages $(\Delta \mathrm{E}=$ 1.95 and 1.94 , respectively) at day 3 . The statistical results also showed that all three packaging materials used did not have an impact on the overall color difference of the Ceylon spinach during storage at $10 \pm 1{ }^{\circ} \mathrm{C}$.

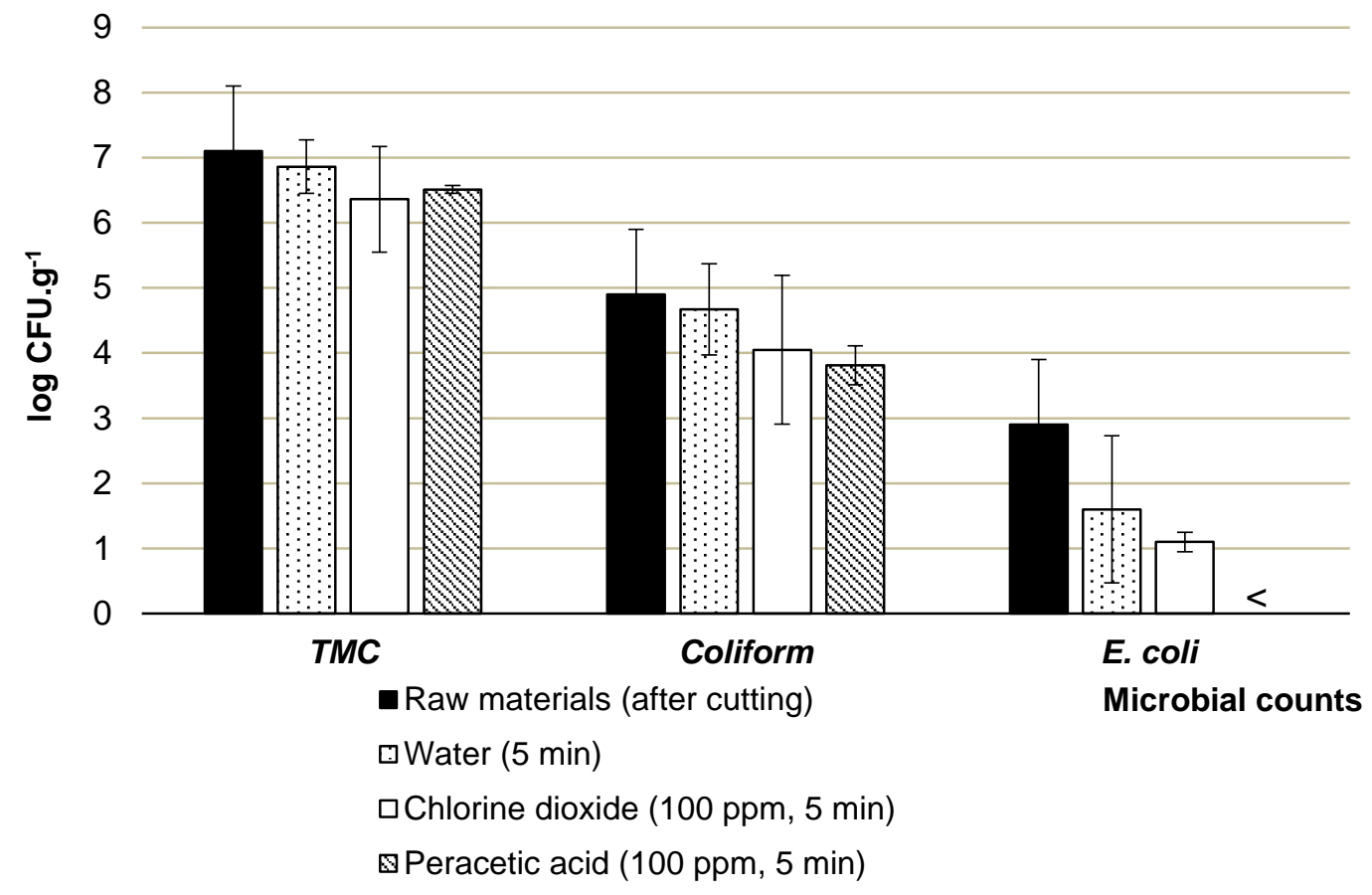

Figure 1. Microbial counts on the Ceylon spinach after being washed with water, chlorine dioxide, or peracetic acid (PAA)

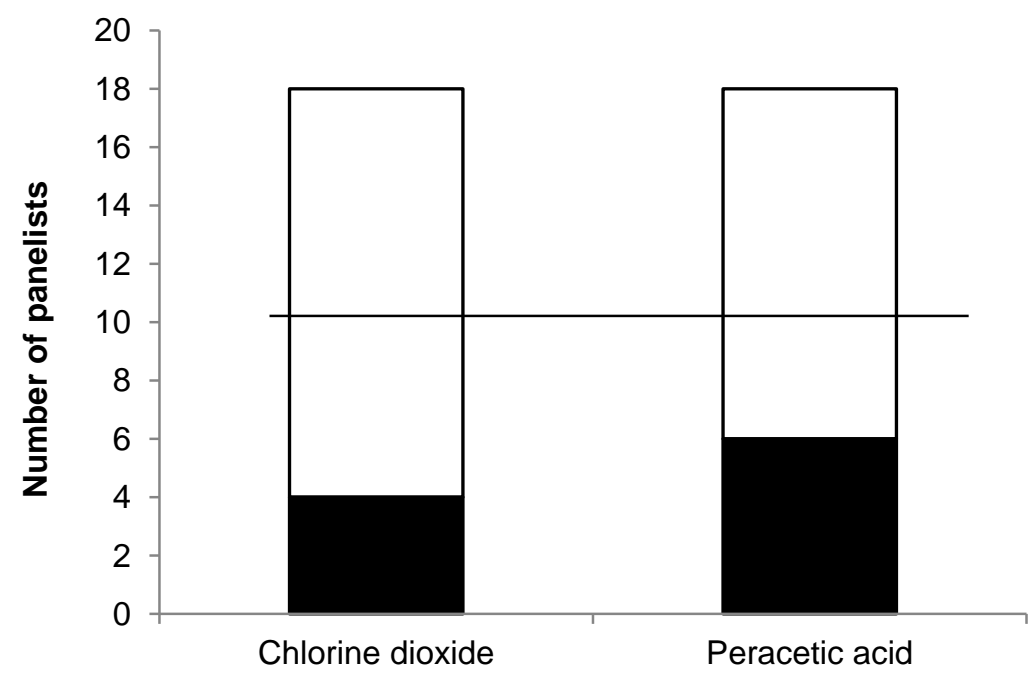

Figure 2. Sensory test of Ceylon spinach treated with chlorine dioxide or peracetic acid water at 100ppm for 5 minutes. $\square$ number of panelists choosing the wrong sample as the odd sample, number of panelists choosing the correct sample as the odd sample. The line (-) shows the minimum number of correct answers needed to have a significant difference in sensory qualities between series $(\alpha=0.05)$. 


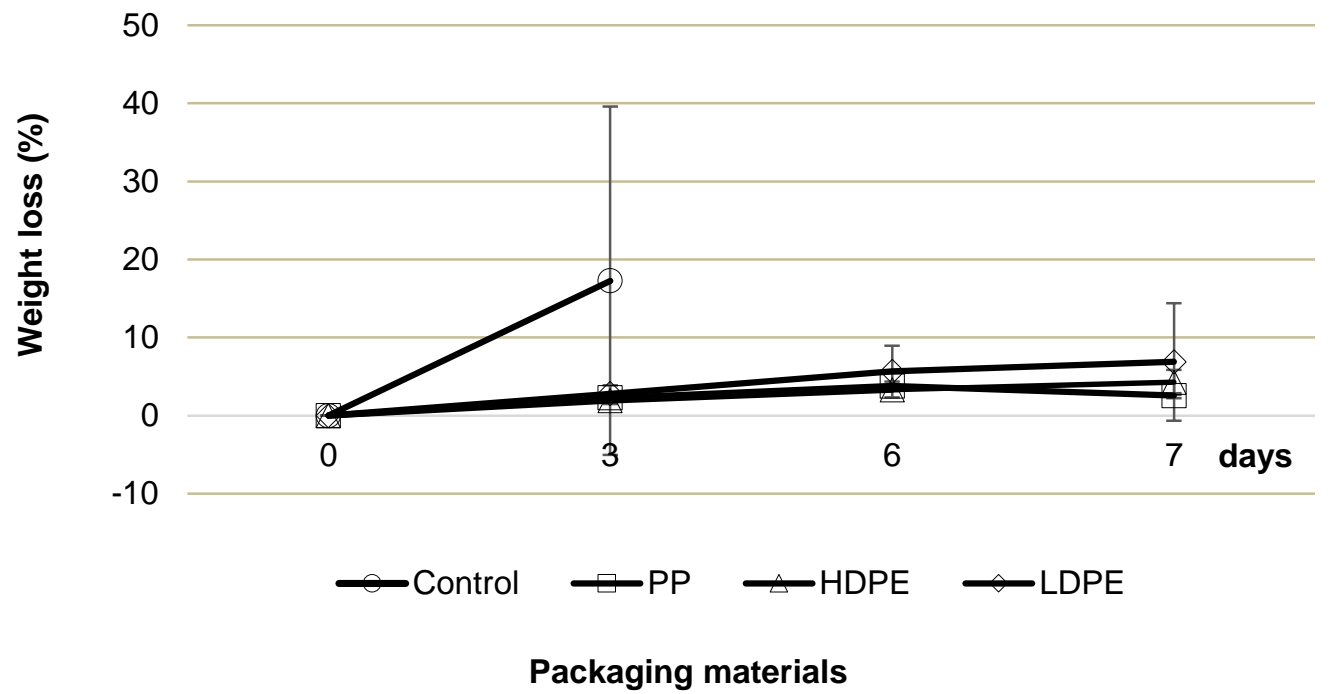

Figure 3. Weight loss of the Ceylon spinach during storage

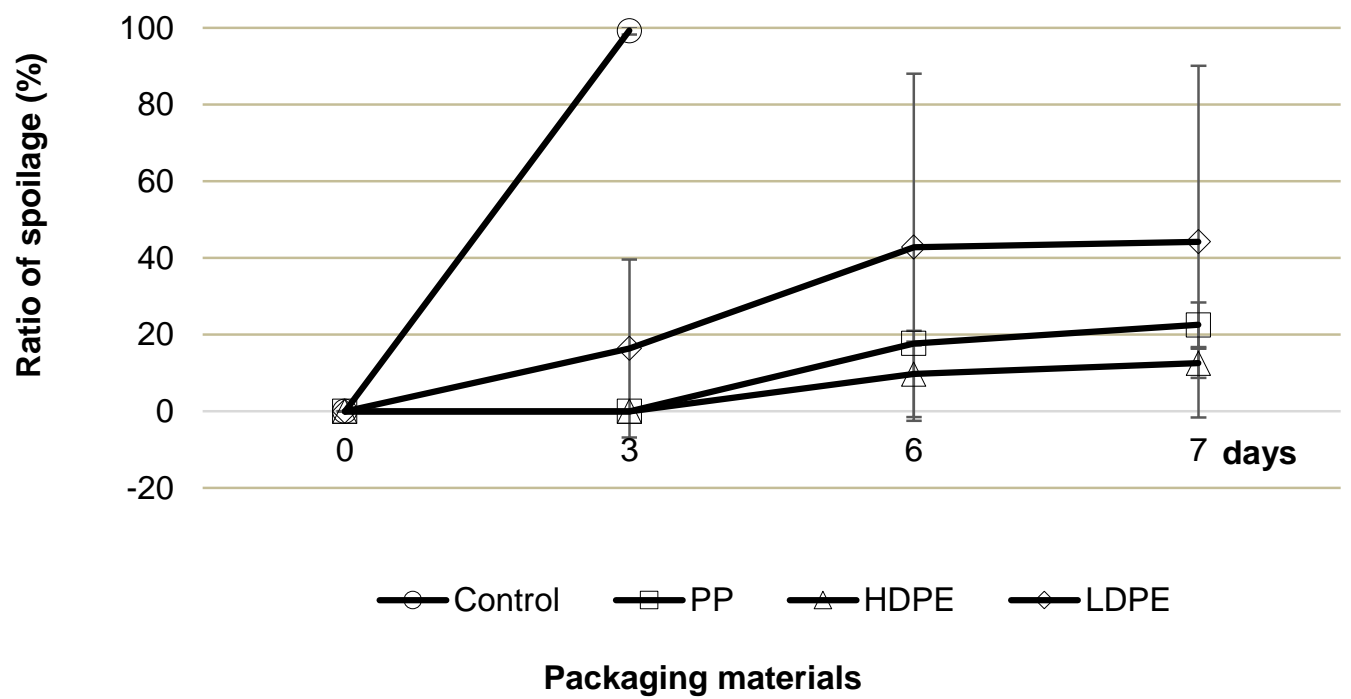

Figure 4. Rate of spoilage of the Ceylon spinach during storage

The effects of the packaging materials on the $\mathrm{pH}$ value of the spinach during storage at 10 $\pm 1^{\circ} \mathrm{C}$ are shown in Figure 5. The initial $\mathrm{pH}$ value of the spinach was $6.4 \pm 0.14$. The $\mathrm{pH}$ values ranged from 6.36 to 6.5 during storage. The type of packaging material did not influence the $\mathrm{pH}$ value of the Ceylon spinach during storage.
Vitamin $\mathbf{C}$ changes of the spinach during storage

Vitamin $\mathrm{C}$, including ascorbic acid and dehydroascorbic acid, is one of the most important nutritional quality factors in many horticultural crops and has many biological activities in the human body. More than $90 \%$ of vitamin $\mathrm{C}$ in the human diet is supplied by fruits and vegetables, especially green leafy 
vegetables (Lee \& Kader, 2000; Citak \& Sonmez, 2010). In this experiment, changes in vitamin $\mathrm{C}$ contents of the Ceylon spinach were also determined during storage (Table 2).

Generally, a decrease in the vitamin C content of the Ceylon spinach was observed in all the packed samples after 7 days at $10 \pm 1^{\circ} \mathrm{C}$ (Table 2). The vitamin $\mathrm{C}$ content of the unpackaged samples reduced rapidly after 3 days (loss of $82 \%$ ). Although the packaging materials delayed the loss of vitamin $\mathrm{C}$ of the Ceylon spinach during storage, the vitamin $\mathrm{C}$ content was not significantly different among the three packaging materials. At day 7, the loss of vitamin $\mathrm{C}$ of the Ceylon spinach was $78-86 \%$ compared to day 0. Gil et al. (1999) found that the decrease of vitamin $\mathrm{C}$ of fresh-cut spinach both in air and MAP packaging was up to $50 \%$ after 3 days of storage at $10^{\circ} \mathrm{C}$.

\section{Microbial quality of the spinach during storage}

\section{Total aerobic mesophilic counts}

The results of the total aerobic mesophilic counts (TMC) of the spinach during storage at $10 \pm 1{ }^{\circ} \mathrm{C}$ (with a relative humidity of $44-60 \%$ ) in different packaging materials are shown in Figure 6. The initial total mesophilic counts of the Ceylon spinach were from 7.0 to $7.3 \mathrm{log}$

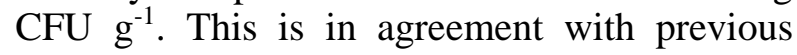
studies that showed initial TMC ranged from 2 to $8 \log$ CFU g ${ }^{-1}$ (Lee et al., 2013; Ottesen et al., 2013; Gu et al., 2018). Samples washed with peracetic acid (100ppm, 5min) had initial TMC values (at day 0 ) of $5.3 \pm 0.4 \log \mathrm{CFU} \mathrm{g}{ }^{-1}$. As recommended by Debevere et al. (2006), the microbiological criteria of TMC for fresh vegetables was targeted at $5 \log \mathrm{CFU} \mathrm{g} \mathrm{g}^{-1}$ at the end of shelf-life, and an acceptable limit of $8 \mathrm{log}$ $\mathrm{CFU} \mathrm{g}{ }^{-1}$. Therefore, the initial microbiological

Table 1. Effects of the packaging materials on the overall color difference $(\Delta \mathrm{E})$ of the Ceylon spinach during storage at $10 \pm 1^{\circ} \mathrm{C}$

\begin{tabular}{ccccc}
\hline \multirow{2}{*}{ Day } & \multicolumn{4}{c}{ Overall color difference $(\Delta \mathrm{E})$} \\
\cline { 2 - 5 } & Control & PP & HDPE & LDPE \\
\hline 0 & $0^{\mathrm{a}}$ & $0^{\mathrm{a}}$ & $0^{\mathrm{a}}$ & $0^{\mathrm{a}}$ \\
3 & $2.94^{\mathrm{b}} \pm 0.23$ & $1.95^{\mathrm{ab}} \pm 0.49$ & $1.94^{\mathrm{ab}} \pm 1.14$ & $1.72^{\mathrm{a}} \pm 0.13$ \\
6 & $\mathrm{NA}$ & $2.25^{\mathrm{a}} \pm 1.59$ & $1.22^{\mathrm{a}} \pm 0.53$ & $1.52^{\mathrm{a}} \pm 0.60$ \\
7 & $\mathrm{NA}$ & $1.72^{\mathrm{a}} \pm 0.13$ & $0.99^{\mathrm{a}} \pm 0.56$ & $1.01^{\mathrm{a}} \pm 0.21$ \\
\hline
\end{tabular}

Note: Unpackaged samples served as the control; Values with the same letter within the same row are not significantly different at $P$ <.05; NA: Not analyzed.

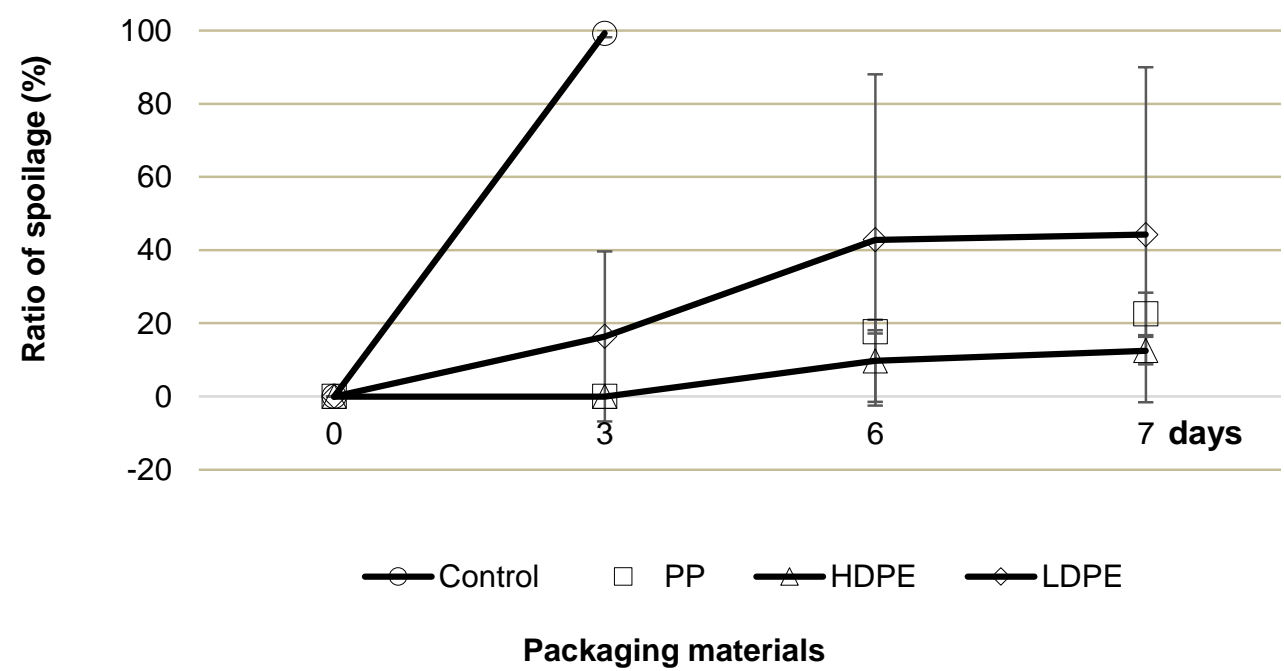

Figure 5. Changes in the $\mathrm{pH}$ of the Ceylon spinach during storage 
Effect of packaging materials and disinfectants on quality changes of Ceylon spinach during storage

Table 2. Changes in vitamin $\mathrm{C}$ contents of the Ceylon spinach in different packaging materials during storage at $10 \pm 1^{\circ} \mathrm{C}$

\begin{tabular}{ccccc}
\hline \multirow{2}{*}{ Day } & \multicolumn{4}{c}{ Changes in vitamin C $(\mathrm{mg} / 100 \mathrm{~g}$ dry weight $)$} \\
\cline { 2 - 5 } & Control & PP & HDPE & LDPE \\
\hline 0 & $30.79^{\mathrm{a}} \pm 2.77$ & $30.79^{\mathrm{a}} \pm 12.77$ & $30.79^{\mathrm{a}} \pm 12.77$ & $30.79^{\mathrm{a}} \pm 12.77$ \\
3 & $5.53^{\mathrm{a}} \pm 3.36$ & $22.55^{\mathrm{a}} \pm 14.70$ & $16.05^{\mathrm{a}} \pm 10.30$ & $15.36^{\mathrm{a}} \pm 12.46$ \\
6 & $\mathrm{NA}$ & $8.07^{\mathrm{a}} \pm 1.06$ & $5.93^{\mathrm{a}} \pm 2.76$ & $6.21^{\mathrm{a}} \pm 2.17$ \\
7 & NA & $6.42^{\mathrm{a}} \pm 2.27$ & $6.54^{\mathrm{a}} \pm 1.28$ & $4.06^{\mathrm{a}} \pm 2.38$ \\
\hline
\end{tabular}

Note: Unpackaged samples served as the control; Values with the same letter within the same row are not significantly different at $P$ $<0.05$; NA: Not analyzed.

quality of the Asian spinach was acceptable. No stored samples exceeded $8 \log \mathrm{CFU} \mathrm{g}{ }^{-1}$ after 6 days of storage. The shelf-life of the samples in the PP and HDPE packages can be extended to day 7 with TMC counts of 7.8 and $7.7 \log$ CFU g ${ }^{-1}$, respectively.

\section{Total yeasts and molds}

Generally, yeast and mold counts of the samples in all the packaging materials increased gradually during storage at $10 \pm 1{ }^{\circ} \mathrm{C}$ (Figure 7). The initial counts of yeasts and molds were 3.6 $\pm 0.7 \log \mathrm{CFU} \mathrm{g} \mathrm{g}^{-1}$. This was in line with the study of Debevere et al. (2006) who reported a tolerance limit of $4 \log \mathrm{CFU} \mathrm{g}{ }^{-1}$. During storage, all the samples showed rapid growth of yeasts and molds after day 3. Particularly, the total yeasts and molds of the samples in the PP package increased rapidly during storage. At day 7 , the yeast and mold counts in the PP were $5.2 \pm 0.1 \log \mathrm{CFU} \mathrm{g}^{-1}$, whereas the counts in the HDPE and LDPE packaging were $4.5 \pm 0.4$ and $4.4 \pm 0.6 \log \mathrm{CFU} \mathrm{g}^{-1}$, respectively. The recommended acceptable limit of yeasts and molds is $5 \log$ CFU g ${ }^{-1}$ (Debevere et al., 2006). The Ceylon spinach stored in LDPE as well as HDPE can be maintained up to 7 days at $10 \pm$ $1^{\circ} \mathrm{C}$ before becoming unacceptable for human consumption.

\section{Sensory evaluation}

Sensory evaluation was implemented on the characteristics of the Asian spinach to evaluate the color, odor, texture, and overall changes during storage (Figure 8). At day 0, the color, odor, and texture of the Asian spinach showed very high acceptability with scores of 4.6-4.8. Rapid changes in terms of the sensory aspects were observed in the control samples during storage (scores of 2.1-3.4 at day 3).
The spoilage of vegetables may result from the degradation of physiological and sensory characteristics (color, texture, and odor) as well as from microbiological degradation (Kakade et al., 2015). In this study, the sensory quality had a high correlation with the chemical and microbiological quality. The samples stored in the PP and HDPE packages (both had an overall score of 4) were better than those packed in LDPE (overall score of 3). According to the results of this study, packaging the Ceylon spinach in LDPE at $10 \pm 1^{\circ} \mathrm{C}$ is recommended if the spinach is used within 6 days, while packaging the Ceylon spinach in the PP or HDPE packages extends the shelf-life up to 7 days. More importantly, after 7 days of storage, the Ceylon spinach in the HDPE package had better quality compared to those packed in PP based on the microbiological quality and spoilage rate. Therefore, the HDPE package is suggested to prolong the quality of the Ceylon spinach during storage.

\section{Conclusions}

Ceylon spinach should first be decontaminated with peracetic acid (100ppm for 5 minutes) before being packed then stored at $10 \pm 1{ }^{\circ} \mathrm{C}$. The results indicated that the use of PP or HDPE packages might optimally prolong the shelf-life of the Ceylon spinach up to 7 days. The Ceylon spinach in the LDPE packaging is recommended if the produce is used within 6 days, while the Ceylon spinach in HDPE had better quality compared to those packed in PP based on the microbiological quality and spoilage rate. Therefore, the HDPE packaging material is recommended for storage of Ceylon spinach at $10 \pm 1^{\circ} \mathrm{C}$. 


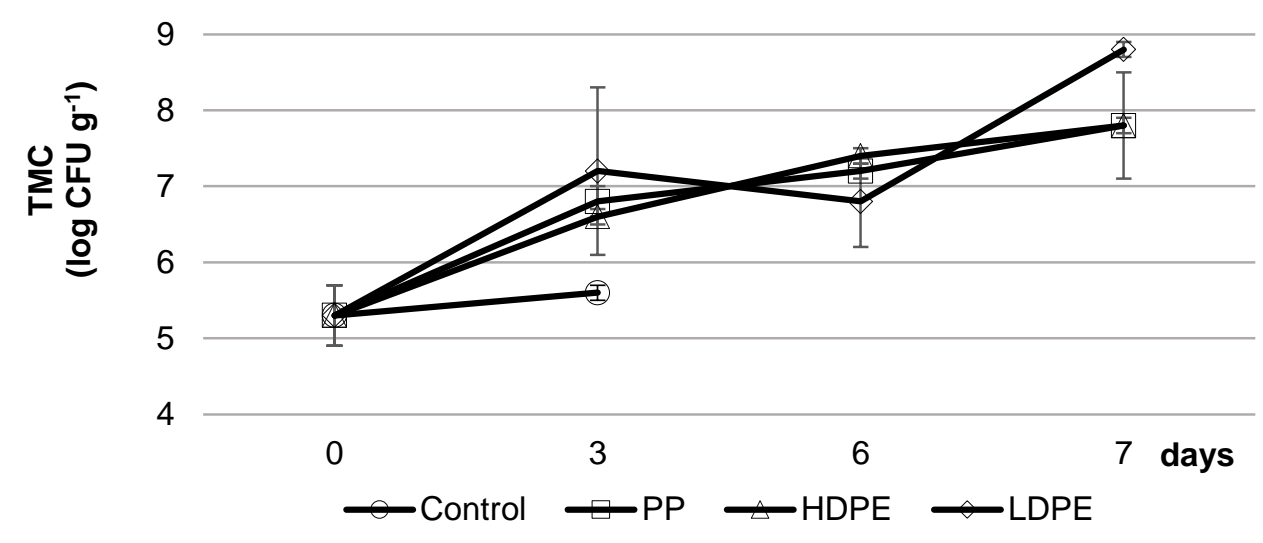

Packaging materials

Figure 6. Total aerobic mesophilic counts (TMC) on the spinach during storage

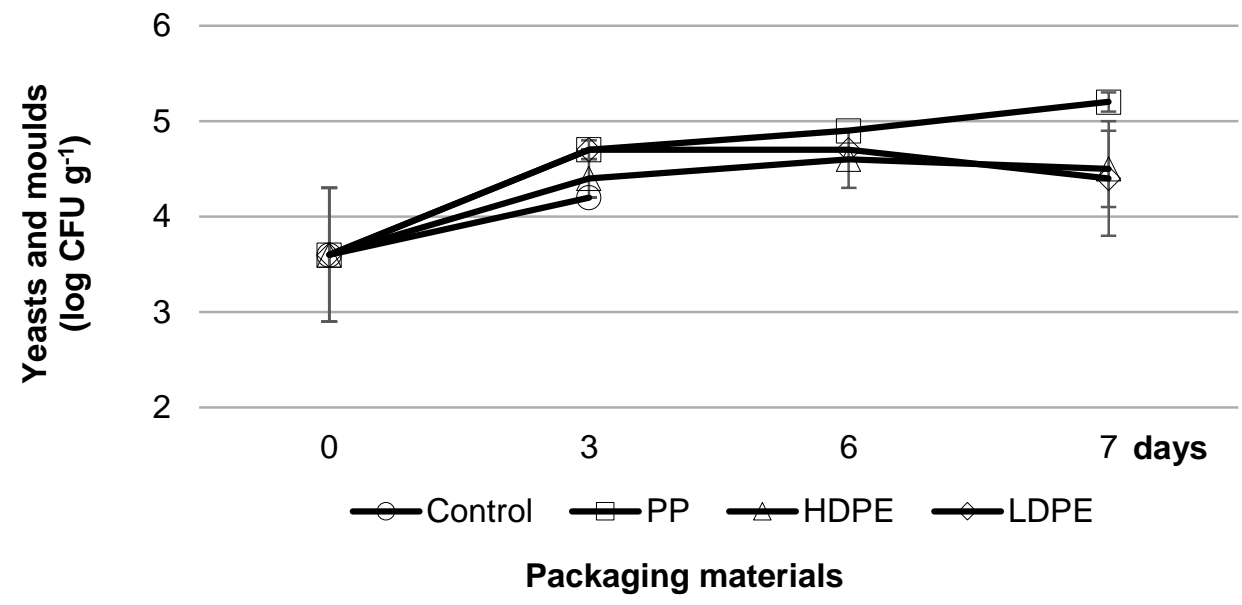

Figure 7. Total yeast and mold counts of the Ceylon spinach during storage

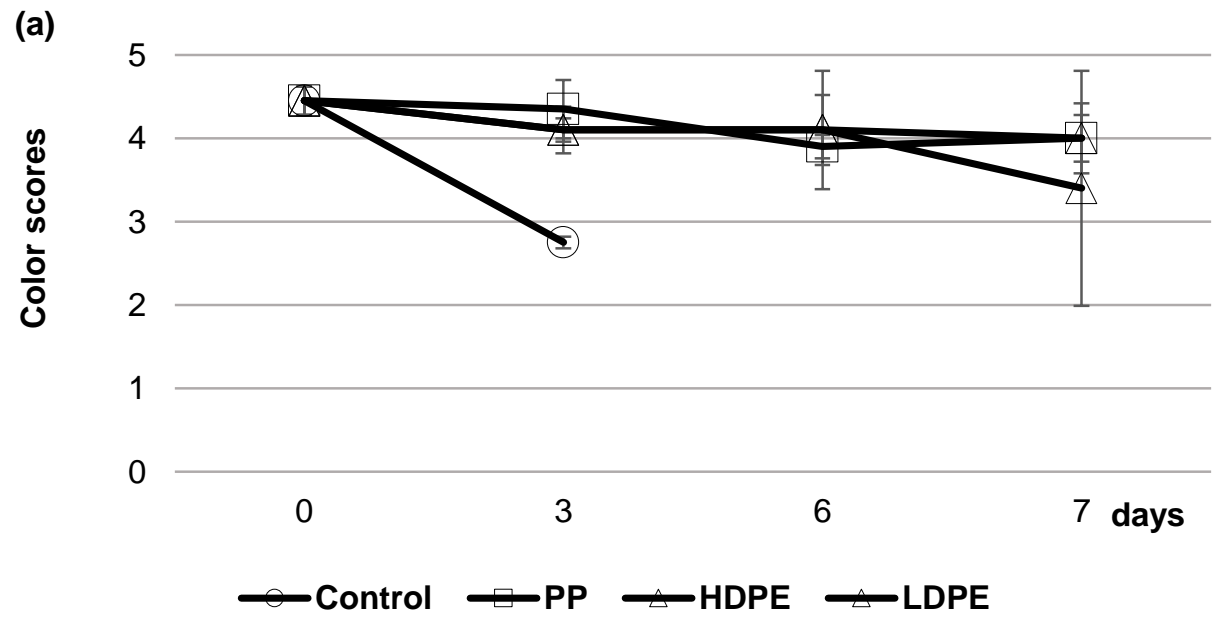


(b)
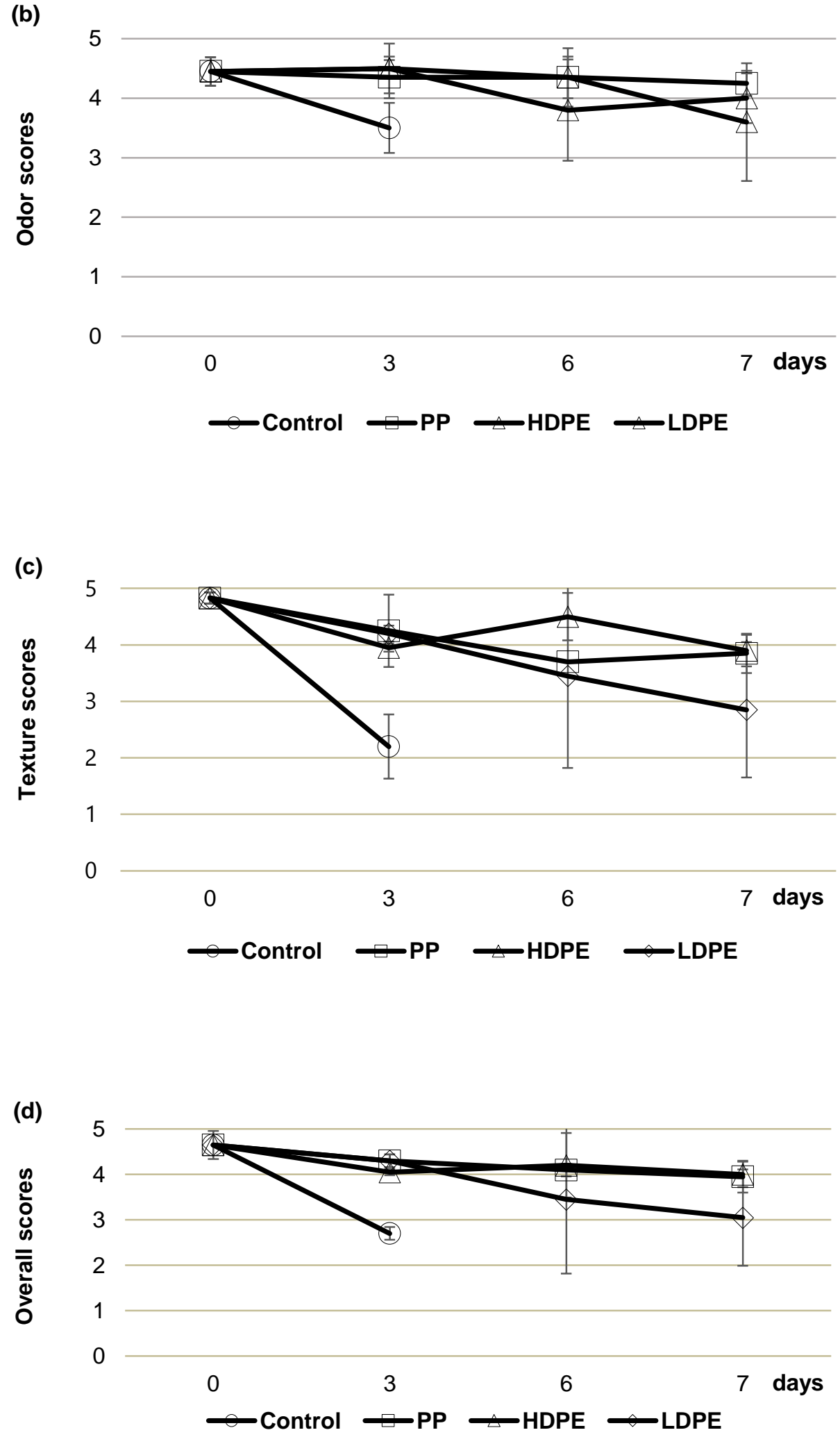

Figure 8. Sensory changes of (a) color, (b) odor, (c) texture, and (d) overall attributes of the Ceylon spinach during storage 


\section{Acknowledgements}

We would like to thank Ms. Pham Hong Nhi and Mr. Dinh Van Khanh Linh for their assistance in this study.

\section{References}

Allende A., Aguayo E. \& Artés F. (2004). Microbial and sensory quality of commercial fresh processed red lettuce throughout the production chain and shelf life. International Journal of Food Microbiology. 91: 109117.

Arturo-Schaan M., Sauvager F., Mamez C., Gougeon A. \& Cormier M. (1996). Use of peracetic acid as a disinfectant in a water-treatment plant: effect on the plasmid contents of Escherichia coli strains. Current Microbiology. 32: 43-47.

Barbosa L. d. N., Carciofi B. A. M., Dannenhauer C. É. \& Monteiro A. R. (2011). Influence of temperature on the respiration rate of minimally processed organic carrots (Daucus Carota L. cv. Brasília). Food Science and Technology. 31: 78-85.

Citak S. \& Sonmez S. (2010). Effects of conventional and organic fertilization on spinach (Spinacea oleracea L.) growth, yield, vitamin $\mathrm{C}$ and nitrate concentration during two successive seasons. Scientia Horticulturae. 126: 415-420.

Costa C., Lucera A., Conte A., Mastromatteo M., Speranza B., Antonacci A. \& Del Nobile M. (2011). Effects of passive and active modified atmosphere packaging conditions on ready-to-eat table grape. Journal of Food Engineering. 102: 115-121.

Debevere J., Uyttendaele M., Devlieghere F. \& Jacxsens L. (2006). Microbiological guide values and legal microbiological criteria. Laboratory of Food Microbiology and Food Preservation, Ghent University, Ghent, Belgium.

Demirci A. \& Ngadi M. O. (2012). Microbial decontamination in the food industry: Novel methods and applications. Elsevier.

Deshmukh S. \& Gaikwad D. (2014). A review of the taxonomy, ethnobotany, phytochemistry and pharmacology of Basella alba (Basellaceae). Journal of Applied Pharmaceutical Science. 4: 153-165.

Gil M. I., Ferreres F. \& Tomás-Barberán F. A. (1999). Effect of postharvest storage and processing on the antioxidant constituents (flavonoids and vitamin C) of fresh-cut spinach. Journal of Agricultural and Food Chemistry. 47: 2213-2217.

Graça A., Esteves E., Nunes C., Abadias M. \& Quintas C. (2017). Microbiological quality and safety of minimally processed fruits in the marketplace of southern Portugal. Food control. 73: 775-783.

Gu G., Ottesen A., Bolten S., Ramachandran P., Reed E., Rideout S., Luo Y., Patel J., Brown E. \& Nou X.
(2018). Shifts in spinach microbial communities after chlorine washing and storage at compliant and abusive temperatures. Food Microbiology. 73: 73-84.

Jacobsson A., Nielsen T. \& Sjöholm I. (2004). Effects of type of packaging material on shelf-life of fresh broccoli by means of changes in weight, colour and texture. European Food Research and Technology. 218: 157-163.

Jin H. H. \& Lee S. Y. (2007). Combined effect of aqueous chlorine dioxide and modified atmosphere packaging on inhibiting Salmonella Typhimurium and Listeria monocytogenes in mungbean sprouts. Journal of Food Science. 72: M441-M445.

Joshi K., Mahendran R., Alagusundaram K., Norton T. \& Tiwari B. (2013). Novel disinfectants for fresh produce. Trends in Food Science \& Technology. 34: 54-61.

Kakade A., More P., Jadhav S. \& Bhosle V. (2015). Shelf life extension of fresh-cut spinach. International Journal of Agriculture, Environment and Biotechnology. 8: 609.

Kitis M. (2004). Disinfection of wastewater with peracetic acid: a review. Environment International. 30: 47-55.

Kotzekidou P. \& Bloukas J. (1996). Effect of protective cultures and packaging film permeability on shelf-life of sliced vacuum-packed cooked ham. Meat Science. 42: 333-345.

Lee M., Lee D. Y., Kim M.-D., Won J. Y., Yune Y.-N., Lee T. Y., Choi D. \& Ko Y.-G. (2013). Selective coverage of the left subclavian artery without revascularization in patients with bilateral patent vertebrobasilar junctions during thoracic endovascular aortic repair. Journal of Vascular Surgery. 57: 1311-1316.

Lee S. K. \& Kader A. A. (2000). Preharvest and postharvest factors influencing vitamin $\mathrm{C}$ content of horticultural crops. Postharvest Biology and Technology. 20: 207-220.

Li Y., Brackett R., Shewfelt R. \& Beuchat L. (2001). Changes in appearance and natural microflora on iceberg lettuce treated in warm, chlorinated water and then stored at refrigeration temperature. Food Microbiology. 18: 299-308.

Ly Nguyen Binh \& Tong Thi Anh Ngoc (2017). Changes in the quality of fresh catfish (Pangasius hypophthalmus) fillets during refrigerated storage under different types of packaging. Proceedings of the $15^{\text {th }}$ Asean Conference on food science and technology. Science and Technics Publishing House Hanoi. Volume 2. 195-201. ISBN: 987-604-6710006-6.

MARD (2018). Ministry of Agriculture and Rural Development (MARD) (2018). Retrieved from https://www.mard.gov.vn/ThongKe/Lists/BaoCaoTho ngKe/Attachments/132/Baocao_T12_2017.pdf on December 4, 2018. 
Monarca S., Richardso S. D., Feretti D., Grottolo M., Thruston A. D., Zani C., Navazio G., Ragazzo P., Zerbini I. \& Alberti A. (2002). Mutagenicity and disinfection by-products in surface drinking water disinfected with peracetic acid. Environmental Toxicology and Chemistry. 21: 309-318.

Muizniece-Brasava S., Ruzaike A., Dukalska L., Stokmane I. \& Strauta L. (2013). Quality evaluation of ready to eat potatoes' produce in flexible packaging. International Journal of Biological, Veterinary, Agricultural and Food Engineering. 7: 391-396.

Nagar V., Hajare S. N., Saroj S. D. \& Bandekar J. R. (2012). Radiation processing of minimally processed sprouts (dew gram and chick pea): effect on sensory, nutritional and microbiological quality. International Journal of Food Science and Technology. 47: 620626.

Ottesen A. R., Peña A. G., White J. R., Pettengill J. B., Li C., Allard S., Rideout S., Allard M., Hill T. \& Evans P. (2013). Baseline survey of the anatomical microbial ecology of an important food plant: Solanum lycopersicum (tomato). BMC Microbiology. 13: 114

Piagentini A. \& Güemes D. (2002). Shelf life of fresh-cut spinach as affected by chemical treatment and type of packaging film. Brazilian Journal of Chemical Engineering. 19: 383-389.

Ragaert P., Devlieghere F. \& Debevere J. (2007). Role of microbiological and physiological spoilage mechanisms during storage of minimally processed vegetables.
Postharvest Biology and Technology. 44: 185-194.

Sapers G. M. (2001). Efficacy of washing and sanitizing methods for disinfection of fresh fruit and vegetable products. Food Technology and Biotechnology. 39: 305-311.

Silveira A., Conesa A., Aguayo E. \& Artes F. (2008). Alternative sanitizers to chlorine for use on fresh-cut "Galia" (Cucumis melo var. catalupensis) melon. Journal of Food Science. 73: 405-411.

Suryawanshi M. (2008). Minimal processing and packaging studies in potato. UAS, Dharwad.

Tong Thi A. N. (2015). Microbial quality of frozen Pangasius hypophthalmus as influenced by industrial processing in Vietnam. Ghent University. Faculty of Bioscience Engineering, Ghent, Belgium.

Tong Thi A. N., Sampers I., Van Haute S., Samapundo S., Nguyen B. L., Heyndrickx M. \& Devlieghere F. (2015). Decontamination of Pangasius fish (Pangasius hypophthalmus) with chlorine or peracetic acid in the laboratory and in a Vietnamese processing company. International Journal of Food Microbiology. 208: 93-101.

Tong Thi Anh Ngoc, Nguyen Cam Tu, Pham Hong Nhi \& Phan Thi Thanh Que (2018). Evaluation of disinfection efficacy of chlorine dioxide and peracetic acid solutions on decontamination of Ceylon spinach (Basella alba). Journal of Agriculture and Rural Development, August 2018. 206-213 (in Vietnamese).

Varalakshmi B. (2016). Genetic variability in Indian spinach (Basella alba L.). Journal of Horticultural Science. 5: 21-24. 